\title{
História, CUlTuRa e SUBJETIVIDAde: PROBLEMATIZAÇÕES
}

\author{
Flávia Cristina Silveira Lemos ${ }^{\star}$
}

\begin{abstract}
Resumo
Na atualidade, percebemos uma ampliação das discussões teórico-metodológicas do conceito de "cultura". Inúmeros autores têm travado debates e embates no campo das ciências sociais e também das ciências humanas, interrogando-os. Um dos eixos do debate articula-se com o processo de constituição das identidades culturais - tanto os modos de subjetivação produtores de subjetividades capitalistas homogeneizadas como os processos de singularização, na sociedade contemporânea. Este artigo se situa no campo de forças dos denominados estudos culturais, questionando as concepções de cultura que foram institucionalizadas: a cultura como unidade cristalizada; como cultura letrada versus cultura popular e a cultura determinando identidades fixas.
\end{abstract}

Palavras-Chave: Cultura. História. Subjetividade. Homogeneização. Singularidade.

\section{History, CUlTURE AND SUBJECTIVITY: PROBLEMS}

\begin{abstract}
On actuality, we perceive a magnifying of the quarrels theoretician-methodologycs of the concept of "culture". Innumerable authors they have locked discussions and clashes into the field from the social sciences, interrogating-the. One of the axles of the discussion is the constitution of the cultural identities - as many the modes producers of subjectivities capitalistic I eat the peace processes make singular, today. This article if points out in the field of forces of the called cultural studies, to place in question the conceptions that have prevailed: a crystallized unit; culture scholar versus popular culture and the culture determining fixed identities.
\end{abstract}

Keywords: Culture. History. Subjectivity. Homogenity. Singularity.

\footnotetext{
* Psicóloga/UNESP, Mestre em Psicologia e Sociedade/UNESP, Doutoranda em História e Sociedade/UNESP, Bolsista FAPESP. Fonte de financiamento: Bolsista Fapesp. Endereço: SOS 411 - Bloco "P" - Apto 306 - Asa Sul - Brasília / DF, CEP 71010-152.

E-mail: flavazevedo@bol.com.brou flavazevedo@hotmail.com
} 
Temos acompanhado, nas últimas décadas, uma overdose de autores falando de cultura, de identidade e diferença baseando-se nos estudos culturais, na história cultural, na antropologia cultural, na sociologia da cultura. Burke (2001) assinala que haveria, hoje, um momento de efervescência dos chamados estudos culturais. No entanto, aponta para a fragmentação desses estudos e para a dificuldade em definir o que é "cultura". Neste artigo, pretendemos promover um debate problematizador desta questão que nos toca tão de perto, nas ciências humanas de um modo geral.

A história cultural clássica estava ancorada na arte, na literatura e na descrição das idéias. A cultura era considerada um patrimônio e pairava no ar enquanto uma unidade transcendente, descolada da economia, da política e das relações sociais, de acordo com Burke (2001) e Chartier (1990). A nova história ou História Cultural, renovada pelas contribuições das ciências sociais, pretende colocar em causa seus objetos e dar primazia ao modo como os construímos ao estabelecer relações entre os acontecimentos. Chartier (1990) vai afirmar uma história cultural que busca o confronto, localizar as lutas discursivas e de poder no campo do saber. Também afirma a ruptura da história cultural com um sujeito universal e abstrato e a descontinuidade das formações sociais e culturais.

Chartier (1990) relata que a cultura era pensada sob a perspectiva de um legado recebido e também como transmissão de hábitos e costumes de uma geração a outra. No entanto, Chartier (1995) afirma que os objetos não são simplesmente aceitos de modo passivo; eles não são recebidos como uma herança perpetuada por uma tradição. Existe um processo de recepção, de apropriação cultural dos objetos, que são utilizados de diferentes formas. A realidade não é recebida como um arquivo e congelada em uma memória em espaços estanques. As realidades sociais seriam sempre construídas e não simplesmente repassadas.

A memória, para Bergson, é uma duração, um devir, virtualidade que se atualiza (DELEUZE, 2004). A memória também é multiplicidade qualitativa e não totalidade e reminiscência. A memória como a cultura é um conjunto de forças, toda tentativa de aprisioná-la em modelos fixos e estáveis é uma negação da vida, uma reatividade e não uma afirmação da vida. Exaltar os monumentos do passado, concebendo-os a partir de identidades culturais cristalizadas é uma prática de uma vida ressentida, que reduz a pluralidade dos acontecimentos ao conhecido e semelhante. Tudo o que vive é transitório, os objetos são configurações provisórias, resultado de uma luta, de uma tensão de forças que nunca finda.

A realidade não é um dado objetivo, mas o que chamamos de realidade é efeito de um processo de objetivação que remete às práticas concretas dos homens. Os textos, os saberes, a subjetividade e a cultura não são dotados de um sentido intrínseco, absoluto e único a ser desvelado (CHARTIER, 1990).

O modo de ser da civilização ocidental tem se pautado na perspectiva metafísica de mundo e de ser, afirmando a imutabilidade dos objetos, em sua unidade e na possibilidade de controlar tecnicamente os eventos. "A marca da metafísica é a crença na duração" (MOSÉ, 2005, p. 35). A linguagem é um instrumento da cultura que, ao nomear os objetos, paralisa-os em conceitos, conferindo- 
lhes uma suposta estabilidade. Nomear, categorizar, classificar, distribuir os indivíduos em grupos de pertença, divididos por semelhanças como as de raça, as de gênero, as de faixa etária, as de classe é congelar os processos de produção da subjetividade em identidades estáticas, fechando a pluralidade em guetos, impedindo a possibilidade de diferenciação.

A proposta de Certeau (2003), em consonância com a de Chartier, é que pensemos a cultura no plural ao invés de percebê-la como um objeto natural ou como uma unidade. Seria ingênua a visão de cultura como patrimônio, a noção de uma cultura pura primeira, como nos apresentou Arendt (2003). Chartier (1990) e Certeau (2003) propõem a realização de uma sociologia da cultura, em que nos preocuparíamos em interrogar os modos de produção da cultura, como ela é difundida e quais são seus meios de circulação.

Poderíamos perceber como o conceito de durabilidade proposto por Arendt (2003) é colocado em xeque, pois este imprimia uma idéia de permanência dos objetos no mundo, independentemente da manipulação dos agentes sociais que os recebessem.

Arendt (2003) adota o conceito de cultura como cultura de elite; para ela, as obras que duram e que poderiam ser consideradas culturais seriam as produzidas pelos artistas, o que tem sido também bastante questionado pelos historiadores da terceira geração do Annales. É como se somente alguns ilustrados, gênios, heróis canonizados e célebres criassem bens culturais e estes fossem aceitos sem nenhuma transformação. Burke (2001) assinala como o processo de canonização de artistas, de diversos autores e dos denominados cientistas/pesquisadores vem sendo estudado pelos historiadores. Exemplos contundentes que ilustram esta afirmação são os estudos realizados sobre a história dos intelectuais, a história da leitura, a interrogação da função-autor, a crítica às biografias e à microhistória.

Esta divisão entre cultura letrada e cultura popular tem sido alvo de interrogações pelos historiadores e estudiosos das ciências sociais. Para Certeau (2003), não há uma cultura de elite homogênea, assim como não há uma cultura popular oposta, também homogênea, compartilhada por classes sociais distintas. Os costumes e hábitos, comportamentos, modos de ser e modos de existir entrecruzam-se. Há um processo de circulação das práticas culturais entre os diversos grupos sociais. Chartier (1995) afirma que a categoria "cultura popular" é uma classificação erudita, produzida para separar as condutas situadas fora de um modelo tomado como referência que é o da cultura erudita. Os vários etnocentrismos têm se mantido em função de práticas que classificam modos de existir de primitivos, não civilizados, carentes, não desenvolvidos diante das práticas de grupos específicos que se agenciam para controlar a produção e reprodução dos bens culturais.

Por outro lado, também encontramos práticas que afirmam a existência de uma cultura popular homogênea que não se comunica com a cultura letrada. Muitos estudos afirmaram um projeto de aculturação das camadas populares com a emergência dos Estados modernos. 
Considera-se que, $[\ldots]$ as culturas tradicionais, camponesas ou populares, saíram do isolamento, e portanto se desenraizaram, em proveito de uma cultura nacional e republicana. Outra transformação radical situa-se antes e depois do surgimento de uma cultura de massa: supõe-se que os novos instrumentos da mídia tenham destruído uma cultura antiga, oral e comunitária, festiva e folclórica, que era, ao mesmo tempo, criadora, plural e livre. O destino historiográfico da cultura popular é portanto ser sempre abafada, recalcada, arrasada, e, ao mesmo tempo, sempre renascer das cinzas (CHARTIER, 1995, p. 181).

Para Chartier (1995), não podemos mais pensar a cultura popular como carente e dependente da cultura dominante, assim como não devemos romantizála. Não haveria um sistema simbólico unificado e aceito de modo igual pelos membros de uma determinada classe, de um gênero específico, de uma faixa etária ou de qualquer outro grupo. As regras podem ser compartilhadas por um grupo, mas cada um as vivencia de uma maneira diferente. Um indivíduo cumpre algumas, rompe com outras, segue normas de outros grupos, apropria-se de modos de existência de outras categorias sociais, produz bifurcações, linhas de fuga às práticas instituídas. Os camponeses, assim como as classes populares, não foram e são simplesmente opressos como queriam muitos intelectuais marxistas. Foucault (1999) já nos alertou para a positividade das relações de poder e também para a possibilidade de resistência aos processos de sujeição.

Há um espaço entre as normas impostas e o vivido. $\mathrm{O}$ autor não nega que haja modos de agir, viver, sentir e pensar afirmados e outros negados em diferentes épocas, assim como não nega que existam regras coercitivas estabelecidas por certos grupos que formam alianças políticas e impõem um conjunto de regras aos outros. A crítica coloca-se negando uma suposta homogeneidade cultural, "tanto os bens simbólicos como as práticas culturais continuam sendo objeto de lutas sociais, em que estão em jogo sua classificação, suas hierarquizações, sua consagração (ou, ao contrário, sua desqualificação)" (CHARTIER, 1995, p. 184-185).

Foucault (2004) foi um historiador que afirmou o tempo todo a política de silenciamento a que eram submetidos certos grupos sociais. Os discursos são constrangidos por determinadas regras, as dos grupos que se apresentam como os representantes dos saberes da ciência, da política, dos trabalhadores, como os sindicalistas, entre outros que pretendem falar em nome de.

Veyne (1998), ao analisar o trabalho de Michel Foucault, afirmou que para este autor não existiriam objetos naturais, mas práticas que constituem os objetos. E, estas práticas de poder, discursivas e de subjetivação, seriam imanentes aos processos sociais, culturais, políticos, econômicos e históricos. Logo, não teria sentido falar de "cultura" enquanto uma unidade estanque, ou seja, não partiríamos de um objeto a priori, mas tentaríamos mapear um diagrama de forças que se entrecruzam em um embate constante. Tratar-se-ia de cartografar o jogo de relações que formam os objetos-acontecimentos que são raros e singulares, daí a importância das práticas culturais, ancoradas nas práticas vizinhas (imanentes), como já mencionamos. 
Foucault (1999) nos mostra como a noção de poder como repressão, como opressão de uma classe sobre outra, como pressupunha Marx, é problemática, pois, as práticas culturais não são somente expressões da esfera macro-econômica. Hall (2005) assinala como não podemos classificar os processos de discriminação a partir de uma única categoria: gênero, raça ou classe. Uma mulher pobre branca pode exercer domínio sobre uma mulher pobre negra; um homem branco rico não letrado pode ser humilhado por um outro homem branco rico letrado; um adolescente europeu pode sentir-se superior a um outro latino, mesmo que pertencentes à mesma classe social. As relações não são determinadas, em primeira instância, por uma esfera unicamente econômica. No entanto, falar de uma determinação cultural ou social seria, ainda, permanecer em um ponto de vista causal.

De acordo com O'Brien (1995, p. 34), os trabalhos de Foucault podem ser considerados "um modelo para a escrita da história da cultura", pois ele problematizava os extratos históricos de sua própria época. As preocupações de Foucault eram com os modos de agir no presente e como eles estavam em vias de ruptura com o estabelecido.

Foucault, ao analisar as práticas culturais do Ocidente, rejeitava as concepções totalizantes de cultura. Ele estava preocupado com a singularidade dos eventos, com a raridade dos objetos, voltando-se para as práticas que produzem determinado objeto que não pode ser transposto para outras épocas (O’BRIEN, 1995). Tratava-se de derrubar uma lógica causal ancorada na busca de origens e em uma história linear. Apontar as rupturas e não fazer uma história de um objeto natural que iria deslocando-se rumo a um apogeu.

As relações de poder eram o foco. Como efeitos delas, emergiam os novos acontecimentos e não o agrupamento de categorias por semelhança. Tratava-se de observar as heterogeneidades, ou seja, realizar a análise da proveniência e não a busca de origens. Um segundo procedimento seria a análise da emergência, em que nos preocuparíamos com os estados de forças que marcam o aparecimento de um costume ao invés de assinalar o momento final de um processo. Não há por que a História buscar as raízes de uma suposta identidade individual ou coletiva. Em cada inversão das relações de força, teríamos o surgimento de novos objetos (MARTON, 2001). Portanto, não teria sentido buscar nos documentos-acontecimentos vestígios de culturas anteriores para costurar uma linha reta do tempo, apontando as continuidades de certas tradições ao longo da história, querendo rebater as multiplicidades que proliferam em categorias agrupadas por semelhanças.

Foucault (2005), com sua genealogia, criticava a veneração dos monumentos do passado, sua preocupação era apontar as rupturas do presente em relação aos outros períodos. Tratava-se de identificar elementos e descrever relações, organizando e recortando os documentos, abandonando o projeto de uma históriamemória. Estabelecemos séries e descrevemos relações entre elas, constituindo séries de séries, multiplicando os extratos.

Além de Foucault, outros pensadores têm se preocupado com a questão da singularidade, que poderíamos dizer que é a marca unificadora dos estudos culturais, na atualidade. No entanto, em nenhum momento, Foucault propôs uma aná- 
lise histórica e dos processos de subjetivação determinista ou causal. Ele nunca afirmou que a cultura era uma entidade metafísica, pairando acima dos homens. A subjetivação é uma prática concreta, imanente às práticas de poder e às discursivas. Foucault nunca pensou as práticas culturais isoladas das econômicas, das políticas, das sociais e das históricas. Ele, em nenhum momento, falou da singularidade enquanto uma essência; não afirmou uma política da diferença como identidade alternativa. O que ele afirmava era a existência de um processo de subjetivação constante, de diferenciação, de produção de modos de existência (DELEUZE, 2000).

Cardoso Jr. (2002) assinala a diferença entre subjetividade e subjetivação a partir das perspectivas foucaultiana e deleuzeana, ambas, atualizações de Nietzsche. "O processo de subjetivação é um processo de composição de modos de vida que se realiza no domínio dos encontros de corpos" (CARDOSO JR., 2002, p. 190191). A subjetividade seria um momento de parada da subjetivação, seria um movimento de desaceleração. "Um eu, uma identidade, outros nomes da subjetividade, se, por um lado, são pontos de parada no processo de subjetivação, por outro lado, são ancoradouros que garantem a navegação desse mesmo processo" (CARDOSO JR., 2002, p. 190-191). Subjetividade e subjetivação não se opõem, mas se interligam em um mesmo processo. O problema seria viver arrastado pelos fluxos de subjetivação sem paradas ou cristalizar-se em uma subjetividade desvitalizada.

Lyotard (1996) afirma que não podemos esquecer que toda história é produto de sua época, estando de alguma maneira comprometida com as questões de seu tempo. É curioso, para o autor, como justamente no período em que o capital se apropriou dos fluxos culturais e passou a afirmar as diferenças identitárias, passamos a nos ocupar da singularidade. Lyotard assinala que, no capitalismo avançado, a cultura foi capitalizada e tornou-se um universal. Descobrimos o mercado das singularidades e passamos a arquivá-lo, transformando-o em memória.

Guattari (1996, p.16) nos alertou para o processo de produção de subjetividades homogeneizadas a partir do equivalente cultural: "O capital funciona de modo complementar à cultura enquanto conceito de equivalência: o capital ocupase da sujeição econômica, e a cultura, da sujeição subjetiva". Para Guattari, podemos lutar contra os modos de subjetivação normalizantes, desenvolvendo processos de singularização, estabelecendo guerra às máquinas de captura do Estado e do Capitalismo Mundial Integrado, que pretendem transformar tudo em mercadoria para consumidores vorazes.

Estaríamos capturados neste fluxo capitalístico ou teríamos alguma margem de ruptura e resistência a este processo? Este é o desafio que nos é colocado hoje.

A subjetivação apresenta-se historicamente porque ela se embaraça nos poderes e saberes. [...] De um modo geral, podese dizer que os processos de subjetivação dependem, antes de mais nada, da maneira como a linha de subjetivação escapa às relações de poder e aos arquivos do saber (CARDOSO JR., 2002, p. 192). 
Como nos organizar, criando estratégias, produzindo corpos sem órgãos que desmanchem os modos-sujeitos desvitalizados pelos vampiros sugadores que simbolizam o capitalismo contemporâneo. Criar corpos sem órgãos é permitir-se experimentar além do limite orgânico, ou seja, romper com as formas. São as intensidades que povoam os corpos sem órgãos que pedem passagem e desfazem os extratos sociais com suas ordenações rígidas e englobantes (DELEUZE; GUATTARI, 1999). O controle, por mais sutil que seja, nunca é total. A vida escapa ao controle, os fluxos escoam pelos lados, transbordam. Não chegamos a um momento catastrófico, em que não poderia existir mais novidade no mundo, a estilística da existência é possível e imanente a uma ética e política. Somente acreditando no mundo, podemos suscitar novos acontecimentos (ORLANDI, 2002).

\section{REFERÊNCIAS}

ARENDT, H. Entre o passado e o futuro. São Paulo: Perspectiva, 2003.

BURKE, P. Variedades da história cultural. Rio de Janeiro: Civilização Brasileira, 2001.

CARDOSO JR., H. R. Foucault e Deleuze em co-participação no plano conceitual. In: RAGO, M.; ORLANDI, L. B. L.; VEIGA-NETO, A. (Org.). Imagens de Foucault e Deleuze: ressonâncias deleuzeanas. Rio de Janeiro: DP\&A, 2002.

CERTEAU, M. A cultura no plural. Campinas: Papirus, 2003.

CHARTIER, R. A História Cultural entre práticas e representações. Lisboa: Difel, 1990.

. "Cultura Popular": revisitando um conceito historiográfico. Estudos Históricos. Rio de Janeiro, v. 8, n. 16, p. 179-192, 1995.

DELEUZE, G. Bergsonismo. Rio de Janeiro: Ed. 34, 2004.

Conversações. Rio de Janeiro: Ed. 34, 2000.

DELEUZE, G; GUATTARI, F. Mil Platôs: capitalismo e esquizofrenia. Rio de Janeiro: Ed. 34, 1999.

FOUCAULT, M. A ordem do discurso. São Paulo: Loyola, 2004. . Arqueologia do saber. Rio de Janeiro: Forense Universitária, 2005. Vigiar e punir: história da violência nas prisões. Petrópolis: Vozes, 1999. GUATTARI, F. Micropolítica: cartografias do desejo. Petrópolis: Vozes, 1996.

HALL, S. A identidade cultural na pós-modernidade. Rio de Janeiro: DP\&A, 2005.

LYOTARD, J-F. Moralidades pós-modernas. Campinas, SP: Papirus, 1996. 
Flávia Cristina Silveira Lemos

MARTON, S. Extravagâncias: ensaios sobre a filosofia de Nietzsche. São Paulo: Discurso: UNIJUÍ, 2001.

MOSÉ, V. Nietzsche: e a grande política da linguagem. Rio de Janeiro: Civilização Brasileira, 2005.

O’BRIEN, P. A História da cultura de Michel Foucault. In: HUNT, L. (Org.). A nova história cultural. São Paulo: Martins Fontes, 1995.

ORLANDI, L. B. L. Que estamos ajudando a fazer de nós mesmos. In: RAGO, M.; ORLANDI, L. B. L.; VEIGA-NETO, A. (Org.). Imagens de Foucaulte Deleuze: ressonâncias deleuzeanas. Rio de Janeiro: DP\&A, 2002.

VEYNE, P. Foucault revoluciona a história. In: . Como se escreve a história. Brasília, DF: UNB, 1998.

Recebido em: dezembro/ 2005 Aceito em: outubro/ 2006 